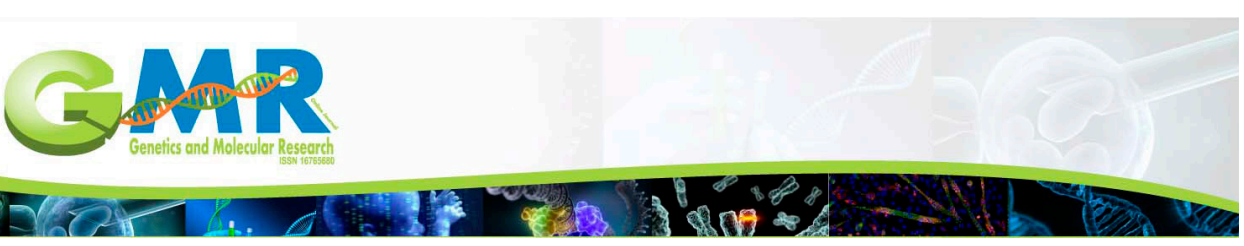

\title{
Sequence analysis of the S1PR1 gene in river buffalo
}

\author{
N.B. Stafuzza ${ }^{1,2}$, B.C.M. Naressi ${ }^{1}$, M.M. Borges ${ }^{1}$ and M.E.J. Amaral-Trusty ${ }^{1}$ \\ 'Departamento de Biologia, Instituto de Biociências, Letras e Ciências Exatas, \\ Universidade Estadual Paulista Júlio de Mesquita Filho, São José do Rio Preto, \\ SP, Brasil \\ 2Departamento de Ciências Exatas, Faculdade de Ciências Agrárias e Veterinárias, \\ Universidade Estadual Paulista Júlio de Mesquita Filho, Jaboticabal, SP, Brasil \\ Corresponding author: M.E.J. Amaral-Trusty \\ E-mail: eamaral@ibilce.unesp.br \\ Genet. Mol. Res. 15 (1): gmr.15016363 \\ Received February 20, 2015 \\ Accepted October 26, 2015 \\ Published January 29, 2016 \\ DOI http://dx.doi.org/10.4238/gmr.15016363
}

ABSTRACT. Recent developments in methodologies for genomic analyses have enabled a significant advance in understanding of the river buffalo genome. The S1PR1 gene has been mapped to buffalo chromosome 6 and bovine chromosome 3; this gene is of interest as it is a candidate for marbling in meat, an important economic trait. Here, we performed next generation sequencing in a buffalo BAC DNA clone and obtained a 54.5-kb sequence encompassing the entire buffalo S1PR1 gene as well as the 27 $\mathrm{kb}$ upstream region and the $22 \mathrm{~kb}$ downstream region. The gene had a total length of $4716 \mathrm{bp}$, including three exons and two introns; exons 1 and 2 were classified as non-protein-coding. In comparison with homologues from other species, the structural organization of buffalo S1PR1 was closest to that of the goat and in both species exon 2 of the gene was non-proteincoding. One hundred and nine repetitive elements were found within the buffalo gene and its boundary regions, with 50 SINE repeats being the most abundant. Alignment of S1PR1 sequences from the Murrah and Mediterranean breeds revealed two nucleotide substitutions (g.1176C $>\mathrm{G}$ 
and g.2740T>C), which represent potential SNPs that could be used in further studies of buffalo genetic structure.

Key words: BAC library; Bubalus bubalis; Murrah; Pyrosequencing; Shingosine-1-phosphate receptor 1

\section{INTRODUCTION}

Sphingosine-1-phosphate receptors (SIPRs) regulate essential cellular processes such as proliferation, migration, cytoskeletal organization, adherens junction assembly, and morphogenesis (Sanchez and Hla, 2004). Although originally known as endothelial differentiation G-protein coupled receptors, the SIPR gene family was renamed once sphingosine-1-phosphate protein (S1P) was established as their ligand (Chun et al., 2010).

Five S1PR proteins have been identified in mammals (S1PR1 to S1PR5). S1PR1 is expressed by the majority of innate and adaptive immune cells such as macrophages, eosinophils, dendritic cells, mast cells, natural killer cells, T cells, B cells, and natural killer T cells (Dorsam et al., 2003; Jolly et al., 2004; Roviezzo et al., 2004; Czeloth et al., 2007; Allende et al., 2007; Hughes et al., 2008; Rivera et al., 2008). The other receptors from this family (S1PR2, S1PR3, S1PR4, and S1PR5) are expressed in only a few cell types of the immune system with an overlapping but distinct pattern of expression according to the tissue (Sanchez and Hla, 2004; Rivera et al., 2008).

The river buffalo (Bubalus bubalis) plays an important role in the worldwide economy through the production of high-quality milk and meat. Genomic analysis of this species has advanced significantly in the last decade with the development of methodologies such as radiation hybrid panels for whole genome mapping (Amaral et al., 2007; Stafuzza et al., 2009) and genomic BAC libraries (Stafuzza et al., 2012) for region-specific resequencing and characterization of target genes (Stafuzza et al., 2014a,b,c).

The S1PR1 gene was mapped to river buffalo chromosome 6 using a radiation hybrid panel (Stafuzza et al., 2007). In cattle, quantitative trait locus analysis revealed that the gene is located on chromosome 3 within a region for marbling of meat and is considered a candidate gene for this trait (Yamada et al., 2006). Single nucleotide polymorphisms (SNPs) within the gene similarly show an association with increased levels of meat marbling in Japanese Black beef cattle (Yamada et al., 2009a,b).

Since S1PR1 might also be an important gene for meat quality in buffalo, we investigated its molecular structure in the Murrah breed, obtained the sequence of the full-length gene and its boundary regions, and searched for repetitive elements that might contribute to buffalo specific genomic signatures. Additionally, the DNA sequence was compared in Murrah and Mediterranean breeds to search for potential SNPs.

\section{MATERIAL AND METHODS}

\section{Bacterial artificial chromosome (BAC) library screening}

The river buffalo BAC library was three-dimensionally screened by PCR as described by Stafuzza et al. (2012) using the following primers: forward 5'-TGGCCCTCTCAGACCTGTTG-3' and reverse 5'-TGGCGAGGAGACTGAACACG-3' (Amaral et al., 2008).

$\mathrm{PCR}$ was performed using a $25-\mu \mathrm{L}$ reaction mixture containing $10 \mathrm{mM}$ Tris- $\mathrm{HCl}, 1.5 \mathrm{mM}$ 
$\mathrm{MgCl}_{2}, 50 \mathrm{mM} \mathrm{KCl}, 10 \mathrm{mM}$ dNTPs, $0.2 \mathrm{mM}$ of each primer, $0.5 \mathrm{U}$ AmpliTaq Gold polymerase (Life Technologies, USA), and $2 \mu \mathrm{L}$ BAC DNA. The amplification conditions were: initial denaturation at $94^{\circ} \mathrm{C}$ for $10 \mathrm{~min}$, followed by 35 cycles at $94^{\circ} \mathrm{C}$ for $30 \mathrm{~s}$ (denaturation), $50^{\circ} \mathrm{C}$ for $30 \mathrm{~s}$ (annealing), $72^{\circ} \mathrm{C}$ for $30 \mathrm{~s}$ (extension), and a final extension at $72^{\circ} \mathrm{C}$ for $7 \mathrm{~min}$. The PCR products were separated on $2 \%$ agarose gels in 1 X TBE buffer containing $0.25 \mathrm{mg} / \mathrm{mL}$ ethidium bromide and photographed under UV light.

\section{Isolation of BAC DNA and pyrosequencing}

The positive clone for S1PR1 was grown in $50 \mathrm{~mL}$ Luria-Bertani medium (Sigma-Aldrich, USA) containing $12.5 \mathrm{mg} / \mathrm{mL}$ chloramphenicol. The BAC DNA was purified using the PhasePrepBAC DNA Kit (Sigma-Aldrich) following the manufacturer instructions.

DNA concentration was determined using a NanoDrop spectrophotometer (Thermo Scientific, USA) and adjusted to $100 \mathrm{ng} / \mu \mathrm{L}$. Amplification of S1PR1 was confirmed by PCR using the purified DNA.

\section{DNA sequencing and bioinformatic analysis}

BAC DNA sequencing was performed by next generation sequencing (NGS) using 454-pyrosequencing - GS FLX Titanium chemistry (Roche) at the 454 Sequencing Center, Branford, CT, USA. The sequence data was assembled using the GS De Novo Assembler version 2.6 (Roche).

Repetitive DNA elements in the Murrah BAC clone sequence were identified by RepeatMasker (http://www.repeatmasker.org/). The Augustus software was used to predict genes from the masked nucleotide sequence (http://bioinf.uni-greifswald.de/augustus/). The predicted gene sequence was aligned against NCBI reference mRNA sequences from Bos taurus using BLAST tools (http://blast.ncbi.nlm.nih.gov/Blast.cgi) and the predicted peptide sequence was aligned against non-redundant protein sequences by BLASTp (protein-protein BLAST) to verify homology among species and identify the predicted genes.

The coordinates of exons, introns, 5'UTR, and 3'UTR of the gene were obtained by alignment of the BAC DNA sequence from the buffalo Murrah breed against the predicted gene sequence available for the Mediterranean breed on NCBI (http://www.ncbi.nlm.nih.gov/ assembly/67671). In addition, the Splign program (http://www.ncbi.nlm.nih.gov/sutils/splign/splign. cgi) was used to identify introns and splice signals.

The Clustal Omega software (http://www.ebi.ac.uk/Tools/msa/clustalo/) was used to align coding gene sequences and amino acids sequences from buffalo (B. bubalis), cow (B. taurus), yak (Bos mutus), sheep (Ovis aries), goat (Capra hircus), horse (Equus caballus), human (Homo sapiens), rat (Rattus norvegicus), mouse (Mus musculus), and chicken (Gallus gallus).

\section{RESULTS}

A clone from the buffalo BAC library was sequenced using the NGS platform at 454/Roche GS FLX. A total of 4014 reads were generated with an average read length of 711 nucleotides arranged in one contig of 54,510 nucleotides providing a $50.54 \mathrm{X}$ coverage and $99.86 \%$ of Q40. The BAC DNA sequence was deposited in GenBank under accession No. KJ635883.

The Augustus software predicted one gene in the DNA sequence showing $99 \%$ identity and $100 \%$ coverage when aligned with bovine sphingosine-1-phosphate receptor 1 (S1PR1) mRNA 
(GenBank accession No. NM_001013585.4) at the NCBI database. Alignment of the predicted peptide against non-redundant protein sequences from the B. taurus database revealed $100 \%$ identity and $100 \%$ coverage with bovine S1PR1 protein (GenBank accession No. NP_001013603.2).

Alignment of our Murrah breed buffalo DNA sequence against the Mediterranean breed buffalo sequence available at NCBI (GenBank accession No. NW_005784259.1, unplaced genomic scaffold scf7180021616379, UMD_CASPUR_WB_2.0) suggested a total length of 4716 bp for the S1PR1 gene. This sequence included three exons (exon 1, 366 bp; exon 2, 1115 bp; and exon 3, $1308 \mathrm{bp}$ ) and two introns (intron 1, $292 \mathrm{bp}$ and intron 2, $230 \mathrm{bp}$ ) and a coding exon/intron size ratio of 1:2.2; the CG level of the sequence was $48.9 \%$. The exon/intron organizations of buffalo S1PR1 and homologs in other bovids (yak, bovine, sheep, and goat), rodents (mouse and rat), horse, human, and chicken are shown in Figure 1. According to the NCBI database, exon 1 and exon 2 are classified as non-protein-coding exons, and similarly for the first $159 \mathrm{bp}$ of exon 3 . Alignment of S1PR1 in Murrah and Mediterranean breeds revealed 99\% identity, with only two nucleotide substitutions in exon 2 ( $\mathrm{g} .1176 \mathrm{C}>\mathrm{G})$ and 3 (g.2740T>C); these variants represent potential SNPs that might be of use for studying the genetic structure of buffalo breeds.

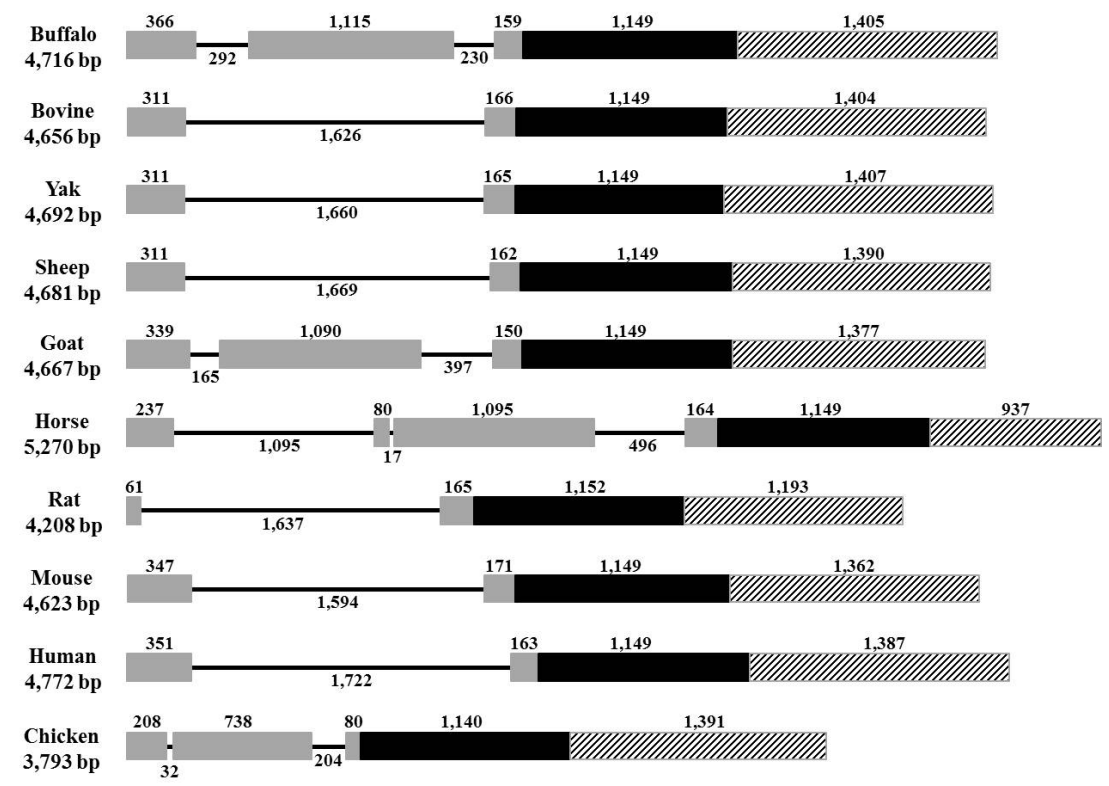

Figure 1. Schematic illustration of the exon/intron organization of S1PR1 in river buffalo (Bubalus bubalis), cow (Bos taurus), yak (Bos mutus), sheep (Ovis aries), goat (Capra hircus), horse (Equus caballus), human (Homo sapiens), rat (Rattus norvegicus), mouse (Mus musculus), and chicken (Gallus gallus). Coding exons are indicated by black boxes while non-protein-coding exons are indicated by gray boxes. Hached boxes represent the 3'UTR regions. Introns are indicated by solid black lines. Numbers indicate the size of exons, introns and 3'UTRs.

\section{DISCUSSION}

Although buffalo S1PR1 showed a similar size to other bovids, its organization showed greater similarity to that of the goat gene: both species contained a non-protein-coding exon 2 . Among the other analyzed vertebrates, the presence of a non-protein-coding exon 2 was only observed in the chicken. S1PR1 showed most difference in gene organization in the horse with the 
presence of three non-protein-coding exons instead of two as in buffalo, goat, and chicken (Figure 1). Comparative sequence analysis between buffalo and bovine genes revealed 56 indels (insertions/deletions), with deletions concentrated in non-protein-coding exon 2 and insertions in the 3'UTR region. A total of 65 nucleotide substitutions was identified and these occurred mainly in introns. Eighteen substitutions were found in the 5'UTR region (g.3312T>C, g.3360T>G, g.3398G>A,

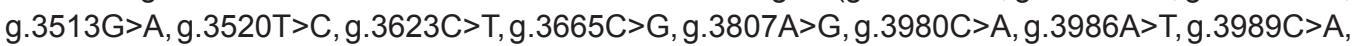
g.3092C $>$ T, g.4207A>G, g.4210T $>$ G, g.4274T $>A$, g.4396T $>C, g .4462 G>A$, and g.4586A $>T$ ) while only six were observed in the 3'UTR region (g.40G>A, g.68A>C, g.79T>C, g.150G>T, g.1979A $>$ T, and g.2033G>A). Nucleotide substitutions in these regions of S1PR1 were previously suggested to be associated with the level of marbling in meat of Japanese Black beef cattle (Yamada et al., 2009a; 2009b). Eight synonymous substitutions were also found in the coding region (g.2280C>T, g.2295T>C, g.2508C>G, g.2682T>C, g.2856T>G, g.2913A>G, g.3015T>C, and g.3102T>C). Comparison of the buffalo S1PR1 coding region with other bovids (goat and sheep) showed 18 nucleotide substitutions (14 synonymous and 4 nonsynonymous); these substitutions resulted in the following amino acids changes in the buffalo protein: Ile173Val, Ser216Ala, Ile219Val, and Ser338Gly (Figure 2).

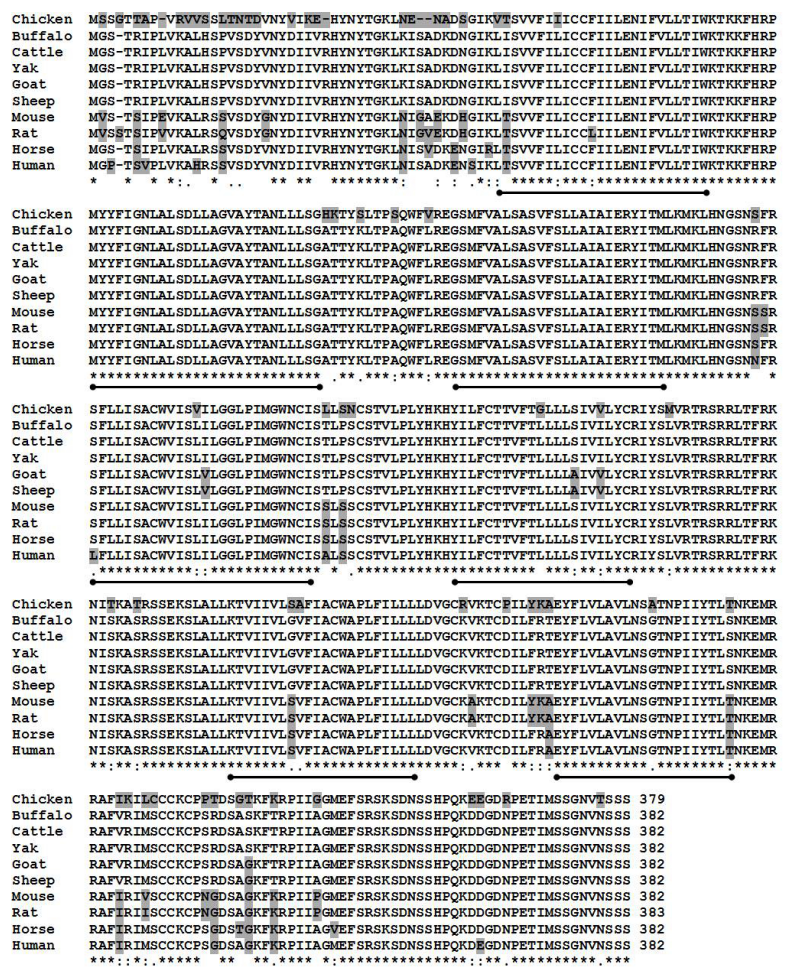

Figure 2. Multispecies amino acid alignment using the Clustal Omega software showing the identity between the buffalo S1PR1 sequence against its counterparts in chicken (GenBank accession No. XP_422305.3), cattle (GenBank accession No. NP_001013603.2), yak (GenBank accession No. XP_005906341.1), goat (GenBank accession No. XP_005678088.1), sheep (GenBank accession No. XP_004002290.1), mouse (GenBank accession No. NP_031927.2), rat (GenBank accession No. NP_058997.1), horse (GenBank accession No. XP_005610319.1), and human (GenBank accession No. NP_001391.2). Amino acids substitutions are highlighted in gray. The black solid lines indicate the seven transmembrane domains of the S1PR1 protein. 
The S1PR1 coding sequence was 1149 nucleotides and encoded a protein of 382 amino acids. This protein is identical in size to that of other mammals, such as bovids (cattle, yak, sheep, and goat), human, and mouse. Chickens have a smaller protein with only 379 amino acids, while the rat has a protein with an additional amino acid (serine at position four) compared to other mammals. Alignment of the amino acid sequences of these various species (Figure 2) indicated high conservation of the transmembrane domain of this protein, as previously described in humans (Rosen et al., 2013). The amino acid sequence of the buffalo S1PR1 protein showed $100 \%$ identity with cattle and yak, 99\% with goat and sheep, 95\% with horse, 94\% with human, 92\% with mouse and rat, and $83 \%$ with chicken (Figure 2). All alignments showed 99\% coverage, except the alignment with amino acid sequences from other bovids that showed $100 \%$ coverage.

The RepeatMasker tool was used to analyze the S1PR1 gene sequence as well as a $27 \mathrm{~kb}$ upstream and a $22 \mathrm{~kb}$ downstream region of the gene to cover a total of $54.5 \mathrm{~kb}$. The region had a GC content of $41.05 \%$ and included 109 repetitive elements encompassing $30.7 \mathrm{~kb}(56.31 \%$ of the region). The rate of repetitive elements in this region was elevated compared to the level of $46.5 \%$ in the whole bovine genome (Adelson et al., 2009).

Analysis of the repetitive elements (109) showed 92 interspersed repeats (50 SINEs, 28 LINEs, 7 LTRs, 6 DNA transposons and 1 unclassified), 5 small RNAs, 2 satellites, 3 low complexity DNAs, and 8 simple tandem repeats. A summary of these elements is given in Table 1 . The large proportion of interspersed repeats in buffalo DNA sequence was expected as this category also represents 40 to $50 \%$ of the total length of the human, mouse and cattle genomes (International Human Genome Sequencing Consortium, 2001; Mouse Genome Sequencing Consortium, 2002; Jurka et al., 2007; Adelson et al., 2009).

Table 1. Repetitive elements in the buffalo BAC DNA sequence. The type of repeat, the total number of repeats, the total length of the repeats, and the relative total size of each element are given.

\begin{tabular}{l|c|c|c}
\hline Type of element & Number & Total length (bp) & Proportion (\%) DNA sequence \\
\hline SINE & 50 & 6,210 & 11.39 \\
\hline LINE $^{2}$ & 28 & 18,348 & 33.65 \\
\hline LTR $^{3}$ & 7 & 1,098 & 2.01 \\
\hline DNA Transposon & 6 & 2,731 & 5.01 \\
\hline Satellite & 2 & 1,094 & 2.01 \\
\hline Small RNA & 5 & 842 & 1.54 \\
\hline Simple repeat & 8 & 265 & 0.49 \\
\hline Low complexity DNA & 3 & 112 & 0.21 \\
\hline
\end{tabular}

${ }^{1}$ Short interspersed sequences. ${ }^{2}$ Long interspersed sequences. ${ }^{3}$ Long terminal repeats transposons.

The two simple repeats in buffalo S1PR1 in the non-protein-coding exon $2\left(\mathrm{GT}_{\mathrm{n}}\right)$ and in intron $2\left(\right.$ TTTC $\left._{n}\right)$ represented $1.46 \%$ of the total length of gene. Both repeats were also observed in the S1PR1 gene of other bovids except for the goat that only had a repeat TTTC . $_{\text {. }}$.

The molecular characterization and the comparative analysis of the buffalo S1PR1 gene corroborate the expected high conservation of its structure when compared with several vertebrates, and provide basic information for future studies of this gene in different buffalo populations such as investigation of the association of polymorphisms with economically important traits, especially those related with meat quality.

\section{Conflicts of interest}

The authors declare no conflict of interest. 


\section{ACKNOWLEDGMENTS}

Research supported by FAPESP (São Paulo Research Foundation, grant \#2011/11889-3) to M.E.J. Amaral-Trusty. CNPq (National Counsel of Technological and Scientific Development) funded the post-doctoral fellowship to N.B. Stafuzza and CAPES (Coordination for the Improvement of Higher Education Personnel) funded the master fellowship to B.C.M. Naressi and M.M. Borges.

\section{REFERENCES}

Adelson DL, Raison JM and Edgar RC (2009). Characterization and distribution of retrotransposons and simple repeats in the bovine genome. Proc. Natl. Acad. Sci. U. S. A. 106: 12855-12860. http://dx.doi.org/10.1073/pnas.0901282106

Allende ML, Zhou D, Kalkofen DN, Benhamed S, et al. (2007). S1P1 receptor expression regulates emergence of NKT cells in peripheral tissues. FASEB J. 22: 307-315. http://dx.doi.org/10.1096/fj.07-9087com

Amaral ME, Owens KE, Elliott JS, Fickey C, et al. (2007). Construction of a river buffalo (Bubalus bubalis) whole-genome radiation hybrid panel and preliminary $\mathrm{RH}$ mapping of chromosomes 3 and 10. Anim. Genet. 38: 311-314. http://dx.doi.org/10.1111/j.1365-2052.2007.01587.x

Amaral ME, Grant JR, Riggs PK, Stafuzza NB, et al. (2008). A first generation whole genome RH map of the river buffalo with comparison to domestic cattle. BMC Genomics 9: 631. http://dx.doi.org/10.1186/1471-2164-9-631

Chun J, Hla T, Lynch KR, Spiegel S, et al. (2010). International Union of Basic and Clinical Pharmacology. LXXVIII. Lysophospholipid receptor nomenclature. Pharmacol. Rev. 62: 579-587. http://dx.doi.org/10.1124/pr.110.003111

Czeloth N, Schippers A, Wagner N, Müller W, et al. (2007). Sphingosine-1 phosphate signaling regulates positioning of dendritic cells within the spleen. J. Immunol. 179: 5855-5863. http://dx.doi.org/10.4049/jimmunol.179.9.5855

Dorsam G, Graeler MH, Seroogy C, Kong Y, et al. (2003). Transduction of multiple effects of sphingosine 1-phosphate (S1P) on T cell functions by the S1P1 G protein-coupled receptor. J. Immunol. 171: 3500-3507. http://dx.doi.org/10.4049/jimmunol.171.7.3500

Hughes JE, Srinivasan S, Lynch KR, Proia RL, et al. (2008). Sphingosine-1-phosphate induces an antiinflammatory phenotype in macrophages. Circ. Res. 102: 950-958. http://dx.doi.org/10.1161/CIRCRESAHA.107.170779

International Human Genome Sequencing Consortium (2001). Initial sequencing and analysis of the human genome. Nature 409: 860-921. http://dx.doi.org/10.1038/35057062

Jolly PS, Bektas M, Olivera A, Gonzalez-Espinosa C, et al. (2004). Transactivation of sphingosine-1-phosphate receptors by FcepsilonRI triggering is required for normal mast cell degranulation and chemotaxis. J. Exp. Med. 199: 959-970. http://dx.doi.org/10.1084/jem.20030680

Jurka J, Kapitonov VV, Kohany O and Jurka MV (2007). Repetitive sequences in complex genomes: structure and evolution. Annu. Rev. Genomics Hum. Genet. 8: 241-259. http://dx.doi.org/10.1146/annurev.genom.8.080706.092416

Rivera J, Proia RL and Olivera A (2008). The alliance of sphingosine-1-phosphate and its receptors in immunity. Nat. Rev. Immunol. 8: 753-763. http://dx.doi.org/10.1038/nri2400

Rosen H, Stevens RC, Hanson M, Roberts E, et al. (2013). Sphingosine-1-phosphate and its receptors: structure, signaling, and influence. Annu. Rev. Biochem. 82: 637-662. http://dx.doi.org/10.1146/annurev-biochem-062411-130916

Roviezzo F, Del Galdo F, Abbate G, Bucci M, et al. (2004). Human eosinophil chemotaxis and selective in vivo recruitment by sphingosine 1-phosphate. Proc. Natl. Acad. Sci. U. S. A. 101: 11170-11175. http://dx.doi.org/10.1073/pnas.0401439101

Sanchez T and Hla T (2004). Structural and functional characteristics of S1P receptors. J. Cell. Biochem. 92: 913-922. http://dx.doi.org/10.1002/jcb.20127

Stafuzza NB, lanella P, Miziara MN, Agarwala R, et al. (2007). Preliminary radiation hybrid map for river buffalo chromosome 6 and comparison to bovine chromosome 3. Anim. Genet. 38: 406-409. http://dx.doi.org/10.1111/j.1365-2052.2007.01612.x

Stafuzza NB, Abbassi H, Grant JR, Rodrigues-Filho EA, et al. (2009). Comparative RH maps of the river buffalo and bovine $Y$ chromosomes. Cytogenet. Genome Res. 126: 132-138. http://dx.doi.org/10.1159/000245912

Stafuzza NB, Abbey CA, Gill CA, Womack JE, et al. (2012). Construction and preliminary characterization of a river buffalo bacterial artificial chromosome library. Genet. Mol. Res. 11: 3013-3019. http://dx.doi.org/10.4238/2012.May.22.6

Stafuzza NB, Borges MM and Amaral-Trusty MEJ (2014a). Comparative analysis of the river buffalo somatostatin gene. Genet. Mol. Res. 13: 10017-10024. http://dx.doi.org/10.4238/2014.November.28.6

Stafuzza NB, Borges MM and Amaral-Trusty MEJ (2014b). Sequence characterization and comparative analysis of the gastrotropin gene in buffalo (Bubalus bubalis). Genet. Mol. Res. 13: 10934-10942. http://dx.doi.org/10.4238/2014. December.19.15 
Stafuzza NB, Borges MM and Amaral-Trusty MEJ (2014c). Genetic analysis of superoxide dismutase 1 gene in murrah river buffalo. J. Anim. Plant Sci. 24: 1869-1875.

Mouse Genome Sequencing Consortium (2002). Initial sequencing and comparative analysis of the mouse genome. Nature 420: 520-562. http://dx.doi.org/10.1038/nature01262

Yamada T, Taniguchi Y, Nishimura S, Yoshioka S, et al. (2006). Radiation hybrid mapping of genes showing intramuscular fat deposition-associated expression changes in bovine musculus longissimus muscle. Anim. Genet. 37: $184-185$. http://dx.doi.org/10.1111/j.1365-2052.2006.01426.x

Yamada T, Sasaki S, Sukegawa S, Miyake T, et al. (2009a). Novel SNP in 5' flanking region of EDG1 associated with marbling in Japanese Black beef cattle. Anim. Sci. J. 80: 486-489. http://dx.doi.org/10.1111/j.1740-0929.2009.00665.x

Yamada T, Itoh M, Nishimura S, Taniguchi Y, et al. (2009b). Association of single nucleotide polymorphisms in the endothelial differentiation sphingolipid G-protein-coupled receptor 1 gene with marbling in Japanese Black beef cattle. Anim. Genet. 40: 209-216. http://dx.doi.org/10.1111/j.1365-2052.2008.01822.x 